\section{JTI}

JOURNAL OF

TRAUMA AND INJURY

\title{
Characteristics of Traffic Accidents on Highways: An Analysis Based on Patients Treated at a Regional Trauma Center
}

Received: October 19, 2020

Revised: December 3, 2020

Accepted: December 10, 2020

\section{Correspondence to}

Tae Hoon Kim, M.D.

Department of Emergency Medicine, Trauma Center, Wonkwang University Hospital, 895 Muwang-ro, lksan 54538, Korea

Tel: $+82-63-859-1188$

Fax: +82-63-859-1197

E-mail: doctor78em@gmail.com ORCID: https://orcid.org/0000-00027683-7259

\author{
Sung Yong Lee, M.D. ${ }^{1}$, Kyung Hoon Sun, M.D., Ph.D. ${ }^{1}$, \\ Chan Yong Park, M.D., Ph.D. ${ }^{2}$, Tae Hoon Kim, M.D. ${ }^{3}$ \\ ${ }^{1}$ Department of Emergency Medicine, Chosun University Hospital, Gwangju, Korea \\ ${ }^{2}$ Department of Trauma Surgery, Seoul National University Hospital, Seoul, Korea \\ ${ }^{3}$ Department of Emergency Medicine, Trauma Center, Wonkwang University Hospital, \\ Iksan, Korea
}

Purpose: There have been increasing concerns about serious traffic accidents on highways. The purpose of this study was to analyze factors affecting traffic accidents on highways and the severity of the resulting injuries.

Methods: This retrospective study was conducted at a regional trauma center. We reviewed 594 patients who had been in 114 traffic accidents on highways from January 2018 to June 2020. We collected demographic data, clinical data, accident-related factors, and meteorological data (weather and temperature).

Results: Environmental risk factors were found to be significantly associated with the incidence of traffic accidents on highways. Injury severity and the death rate were higher in sedans than in any other type of vehicle. Tunnels were the most common location of accidents, accounting for 47 accidents (41.2\%) and 269 injured patients (45.3\%). The injury severity of individuals riding in the driver's seat (front seat) was high, regardless of vehicle type. Three meteorological risk factors were found to be significantly associated with traffic accidents: rainy roads (odds ratio [OR] 2.08; 95\% confidence interval [CI] 1.84-3.29; $p=0.01$ ), icy or snowy roads (OR 5.12; 95\% CI 2.88-7.33; $p<0.01$ ), and foggy conditions (OR 2.94; 95\% CI 2.15-4.03; $p<0.05$ ).

Conclusions: The injury severity of patients was affected by seat position and type of vehicle, and the frequency of accident was affected by the location. The incidence of traffic accidents was strongly influenced by meteorological conditions (rain, snow/ice, and fog).

Keywords: Accidents, traffic; Injury Severity Score; Weather 


\section{INTRODUCTION}

Automobiles are considered to be an essential element of modern society, as they make human life more convenient and expand living space. As income levels have increased in South Korea, the number of registered automobiles has continued to grow, exceeding 23.5 million units in 2019 [1]. This increase in vehicles eventually led to an increase in traffic accidents, and an economic research report was submitted, indicating that traffic accidents impose an enormous burden in terms of economic damage and rehabilitation costs [2]. Both domestically and internationally, researchers have conducted studies on risk factors for the incidence and severity of traffic accidents, and found that the speed of the vehicle, meteorological conditions, and time of day were related factors [3-6]. According to Lee et al. [7], accidents on highways have higher severity and mortality rates than those on local roads, and accidents in the evening and early morning have higher mortality rates than those at other times of day. This is because accidents on highways involve higher vehicle speeds than those on local roads, and injured victims may face delays in reaching emergency medical treatment. As the total length of highways increases, with a concomitant growth in the number of accidents, it is necessary to analyze risk factors for the incidence and severity of traffic accidents on highways to plan an appropriate emergency medical system to improve patients' prognosis. For this reason, the authors conducted a study to analyze the frequency and severity of accidents according to vehicle type, the specific location of the accident, the time of occurrence, and meteorological and road conditions, using data from patients who presented to a regional trauma center due to highway traffic accidents.

\section{METHODS}

This research porject was approved by Institutional Review Board (IRB) of Chosun Univiersity Hosipital (IRB No. 2020-10-006).

\section{Research subjects}

From January 2018 to June 2020, 722 patients (in 137 traffic accidents) who presented to the regional trauma center due to a traffic accident that occurred on a highway with four or more lanes were analyzed. Patients were excluded if they were under the age of 18, were transferred more than 24 hours after the accident from another hospital, or lacked accurate data on accident mechanisms or patient-related characteristics.

\section{Research method}

The study was conducted in a retrospective manner by collecting electronic medical records and trauma-related records for patients who presented to the trauma center due to traffic accidents. The study collected clinical data, including the Revised Trauma Score (RTS), Injury Severity Score (ISS), and Trauma Injury Severity Score (TRISS), which were used as indicators of the severity of trauma; demographic data, such as age and sex; and vital indicators, vital signs, and seat position at the time of the accident. Clinical data, such as length of hospitalization and mortality, were also collected. In addition, traffic accident-related variables included the type of vehicle, the location of the accident on the highway, the time of the accident (dawn: $2 \mathrm{AM}$ to $8 \mathrm{AM}$, daytime: $8 \mathrm{AM}$ to $2 \mathrm{PM}$, evening: 2 PM to $8 \mathrm{PM}$, and night: $8 \mathrm{PM}$ to $2 \mathrm{PM}$ ), highway conditions, and meteorological conditions at the time of the accident were also collected and recorded.

\section{Statistical analysis}

SPSS for Windows version 26.0 (IBM Corp, Armonk, NY, USA) was used for statistical analyses. In the descriptive statistical analysis, quantitative variables were expressed as mean \pm standard deviation, and the categorical variables measured for each item were expressed as frequency and percentage (\%). In multiple comparisons involving multiple variables, post-hoc analysis was performed using the independent-sample $t$-test and the Bonferroni method using one-way analysis of variance (ANOVA). For continuous variables, the analysis was performed using the independent sample $t$-test and logistic regression analysis with the environmental factors related to traffic accidents as independent variables and the frequency of accidents as dependent variables. Statistical findings were considered to be statistically significant when the $p$-value was less than 0.05 . 


\section{RESULTS}

\section{General characteristics of research subjects}

In the 29-month period from January 2018 to June 2020, a total of 137 traffic accidents occurred on highways in the region covered by the regional trauma center where this study was conducted, and 722 patients were confirmed to have been in these accidents. Among them, 594 patients were studied, after the exclusion of 69 patients who were under the age of 18, 43 patients who were transferred to the hospital more than 24 hours after the accident from

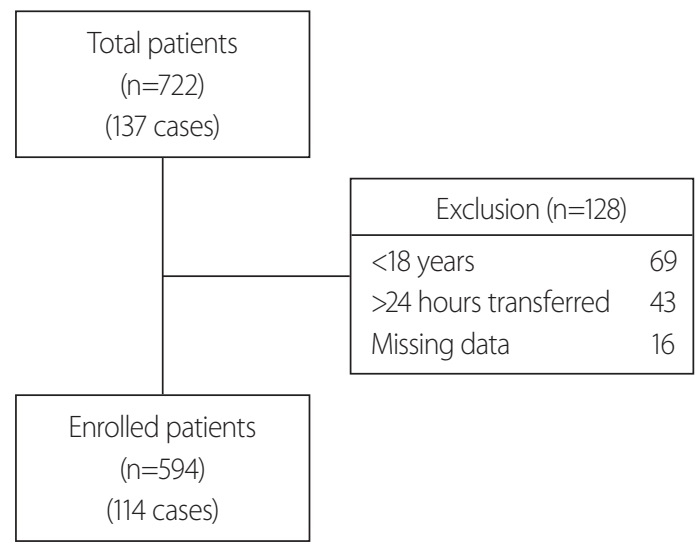

Fig. 1. Enrollment of patients who were in traffic accidents on highways. other hospitals, and 16 patients with insufficient available data. Twenty-three accidents were also excluded because they were related to the excluded patients (Fig. 1). Of the 594 patients who were analyzed, there were more men (335; 56.3\%) than women $(259 ; 43.7 \%)$, and the mean age of the patients was $42.1 \pm 10.8$ years. Accidents involving trucks and sedans were associated with significantly higher trauma severity (ISS: $15.4 \pm 6.3$ and $11.5 \pm 6.3$ points, respectively) than accidents involving other types of vehicles. The mortality rate after 24 hours was also significantly higher for accidents involving trucks and sedans, at 16.7\% and $13.5 \%$, respectively. The hospitalization period of patients who were in sedan accidents was significantly longer (17.2 \pm 10.3 days) than that of patients who were in accidents involving other types of vehicles (Table 1). However, no significant differences in GCS and RTS were observed.

\section{Highway location and accident characteristics}

The location of accidents on the highway was divided into five categories: straight roads, curved roads, roads around tunnels, bridges, and roads with unconfirmed information. The highest number of accidents was found around tunnels was ( $n=47 ; 41.2 \%)$, and the number of patients was also highest for accidents near tunnels $(n=269$; $45.3 \%$ ). The frequency of accidents on straight roads

Table 1. Patients' baseline characteristics according to the type of vehicle involved in the highway accident

\begin{tabular}{|c|c|c|c|c|c|c|}
\hline & Sedan & SUV & VAN & Truck & Bus & $p$-value \\
\hline Patients & 96 & 136 & 94 & 36 & 232 & 0.68 \\
\hline Male & 54 & 94 & 47 & 32 & 98 & \\
\hline Age (years) & $43.8 \pm 10.4$ & $38.6 \pm 9.5$ & $39.4 \pm 11.2$ & $47.2 \pm 8.5$ & $42.1 \pm 14.4$ & 0.78 \\
\hline GCS & $12.7 \pm 2.4$ & $13.1 \pm 1.4$ & $13.5 \pm 1.8$ & $13.8 \pm 1.2$ & $13.7 \pm 1.9$ & 0.35 \\
\hline RTS & $7.1 \pm 1.2$ & $7.6 \pm 0.7$ & $7.4 \pm 0.5$ & $6.8 \pm 0.8$ & $7.6 \pm 0.6$ & 0.96 \\
\hline ISS & $11.5 \pm 6.3$ & $9.5 \pm 3.8$ & $10.2 \pm 5.4$ & $15.4 \pm 6.3$ & $6.5 \pm 2.8$ & 0.04 \\
\hline TRISS & $94.2 \pm 8.6$ & $96.7 \pm 6.2$ & $95.8 \pm 4.6$ & $94.6 \pm 12.2$ & $97.2 \pm 5.4$ & 0.06 \\
\hline Length of HD (days) & $17.2 \pm 10.3$ & $11.5 \pm 6.7$ & $14.2 \pm 8.5$ & $6.5 \pm 4.8$ & $8.5 \pm 5.2$ & 0.03 \\
\hline \multicolumn{7}{|l|}{ Outcomes } \\
\hline Discharge & $76(79.2)$ & $128(94.2)$ & $84(89.4)$ & $28(77.8)$ & $218(93.9)$ & 0.02 \\
\hline Hopeless discharge & $2(2.0)$ & $3(2.2)$ & $0(0.0)$ & $0(0.0)$ & $0(0.0)$ & 0.89 \\
\hline Death in 24 hours & $5(5.2)$ & $1(0.7)$ & $2(2.1)$ & $2(0.5)$ & $4(1.7)$ & 0.72 \\
\hline Death & $13(13.5)$ & $4(2.9)$ & $8(8.5)$ & $6(16.7)$ & $10(4.3)$ & 0.04 \\
\hline
\end{tabular}

Values are presented as mean \pm standard deviation or number (\%).

GCS: Glasgow Coma Scale, RTS: Revised Trauma Score, ISS: Injury Severity Score, TRISS: Trauma and Injury Severity Score, HD: hospital day. 
(33.3\%) and curved roads (12.3\%) was also high (Table 2).

\section{Environmental factors affecting the frequency of traffic accidents}

Logistic regression analysis was used to analyze the relationship of the frequency of traffic accidents on highways with time and meteorological variables such as weather conditions, the ground conditions of the highway, and temperature at the time of the accident. The frequency of accidents was significantly higher at dawn (odds ratio [OR] 2.35 ; 95\% confidence interval $[\mathrm{CI}] 1.92-3.57 ; p=0.01)$ and night (OR 1.95; 95\% CI 1.16-2.65; $p=0.02$ ) than during

Table 2. The locations and injuries of patients who were in traffic accidents on highways

\begin{tabular}{|c|c|c|c|c|c|c|}
\hline & Straight area road & Curved area road & Tunnel area road & Bridge area road & Unconfirmed road & $p$-value \\
\hline Accident cases & $38(33.3)$ & $14(12.3)$ & $47(41.2)$ & $12(10.5)$ & $3(2.6)$ & 0.03 \\
\hline Sedan & $13(11.4)$ & $2(1.8)$ & $18(15.8)$ & $2(1.8)$ & $1(0.9)$ & 0.05 \\
\hline SUV & $12(10.6)$ & $5(4.4)$ & $12(10.6)$ & $2(1.8)$ & $1(0.9)$ & 0.07 \\
\hline VAN & $4(3.5)$ & $3(2.6)$ & $3(2.6)$ & $5(4.4)$ & $0(0.0)$ & 0.55 \\
\hline Truck & $7(6.1)$ & $2(1.8)$ & $9(7.9)$ & $1(0.9)$ & $1(0.9)$ & 0.79 \\
\hline Bus & $2(1.8)$ & $2(1.8)$ & $5(4.4)$ & $2(1.8)$ & $0(0.0)$ & 0.96 \\
\hline Injured patients & $150(25.3)$ & $87(14.6)$ & $269(45.3)$ & $79(13.3)$ & $9(1.5)$ & 0.02 \\
\hline Sedan & $32(5.4)$ & $8(1.3)$ & $45(7.6)$ & $7(1.2)$ & $4(0.7)$ & 0.23 \\
\hline SUV & $44(7.4)$ & $19(3.2)$ & $58(9.8)$ & $11(1.9)$ & $4(0.7)$ & 0.16 \\
\hline VAN & $26(4.4)$ & $11(1.9)$ & $26(4.4)$ & $31(5.2)$ & $0(0.0)$ & 0.89 \\
\hline Truck & $12(2.0)$ & $4(0.7)$ & $16(2.7)$ & $3(0.5)$ & $1(0.2)$ & 0.63 \\
\hline Bus & $36(6.1)$ & $45(7.6)$ & $124(20.9)$ & $27(4.5)$ & $0(0.0)$ & 0.02 \\
\hline
\end{tabular}

Values are presented as number (\%).

Variable factor

Time of accidents (refer: daytime)

Dawn

Evening

Night

Road surface state (refer: clear)

Rain (wet)

Snow (ice)

Fog

Cloud

Temperature (refer: $0^{\circ} \mathrm{C}$ )

Above zero $\left(0^{\circ} \mathrm{C}\right)$

Below zero $\left(0^{\circ} \mathrm{C}\right)$
OR

OR $(95 \% \mathrm{Cl})$

2.35 (1.92-3.57)

$1.89(1.65-2.24)$

$1.95(1.16-2.65)$

$2.08(1.84-3.29)$

$5.12(2.88-7.33)$

2.94 (2.15-4.03)

$1.05(0.55-1.15)$

$1.18(0.68-1.54)$

$4.15(1.80-5.85)$ $p$-value

0.01

0.05

0.02

0.01

0.01

0.02

0.65

0.54

0.01

Fig. 2. Multivariate logistic regression analysis of environmental variables related to traffic accidents. OR: odds ratio, Cl: confidence interval. 
daytime, and more accidents occurred on rainy roads (OR 2.08; 95\% CI 1.84-3.29; $p=0.01$ ), icy roads (OR 5.12; 95\% CI $2.88-7.33$; $p=0.01$ ), and foggy days (OR $2.94 ; 95 \%$ CI $2.15-4.03 ; p=0.02)$ than on sunny days. The frequency of accidents was higher at sub-zero temperatures than at above-zero temperatures (OR 4.15; 95\% CI 1.80-5.85; $p=0.01$ ) (Fig. 2).

\section{Severity prediction according to seat position}

A receiver operating characteristic curve analysis was conducted to determine whether the seat position predicted accident severity, regardless of the car type. The highest severity was found for the driver's seat (area under the curve [AUC] $0.925 ; p<0.01$ ), followed in order by the passenger seat (AUC 0.783; $p<0.01$ ) and rear seat (AUC 0.598; $p<0.01$ ) (Fig. 3).

\section{DISCUSSION}

This study analyzed the characteristics of highway traffic accidents to identify factors related to the frequency of accidents and the severity of patients' injuries. Earlier

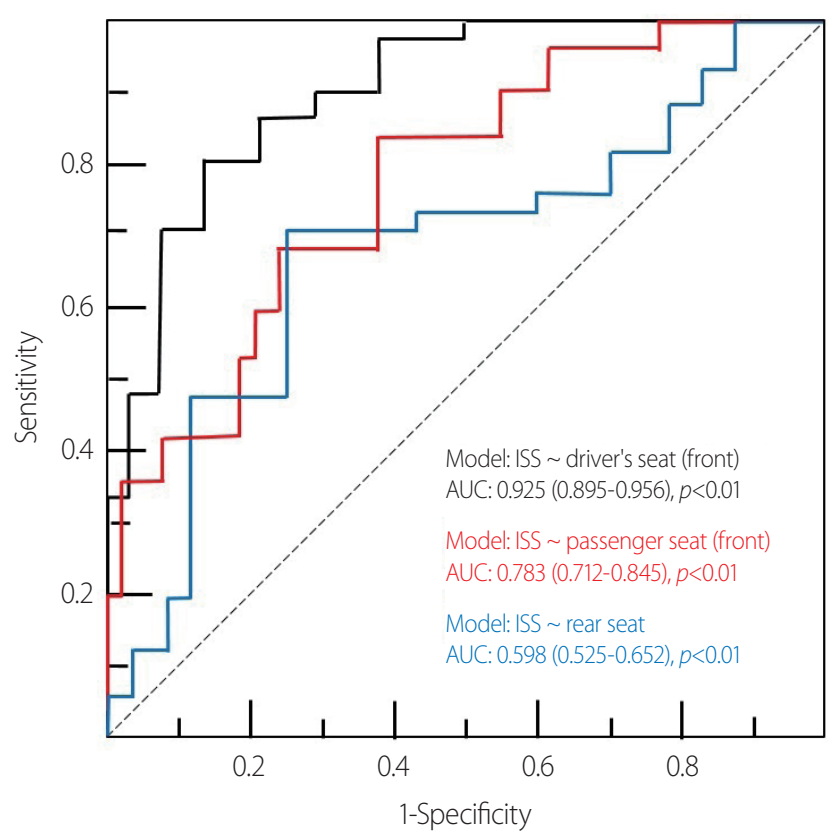

Fig. 3. ROC curves for seat position and an ISS of more than 15 points. ROC: receiver operating characteristic, ISS: Injury Severity Score, AUC: area under the curve. research has demonstrated that the severity of traffic accidents is affected by several factors. Because traffic accidents on highways are highly likely to lead to serious trauma and mass disasters, Anastasopoulos et al. [8] studied the level of accident risk in a specific road section through variable responses using a tobit analysis of severity. Roshandel et al. [9] conducted a systematic review and meta-analysis to develop a method for real-time accident prediction according to traffic volume and road conditions. According to Yannis et al. [10], the mortality and severity of accidents involving trucks and sedans were higher than those involving other types of vehicles. According to Liu et al. [11], the severity of patients' injuries was high in accidents involving large vehicles such as trucks, and highly fatigued patients had severe injuries. In particular, it was reported that the severity of injuries was high among commercial truck drivers. In our study, the severity and mortality of sedan and truck accidents were significantly higher than those of accidents involving other types of cars, aligning with the results of previous research.

According to previous studies of the risk of accidents on highways according to the type of road, the risk of accidents around tunnels was higher, and accidents were more frequent on straight roads than on curved roads [12-14]. According to Han et al. [12], through a simulation experiment of the occurrence of visual impairment in tunnels, the driver's pupil constricts while in a tunnel and the reaction to light is slow; therefore, the risk of traffic accidents increases. In this study, the frequency of traffic accidents in the vicinity of tunnels was also significantly higher than in other locations, and as mentioned above, this is thought to be due to the visual impairment caused by sudden exposure to light when entering or exiting a tunnel.

Gårder [13] studied the characteristics of fatal head-on crashes and concluded that about $67 \%$ of them occurred on straight roads. The reason for this was that high speed limits were associated with the occurrence of serious accidents. The findings of Jones et al. [14] indicate that the frequency and mortality of traffic accidents increased as the degree of road curvature decreased. In recent years, it seems that the increase in the speed of vehicles has been the largest factor contributing to the occurrence of accidents, as projects are under way in Korea to straighten 
highways. In addition, in this study, a significantly higher number of traffic accidents occurred on straight highways than on curved roads. This can be explained in light of the causes pointed out in existing research.

In addition to the shape of roads, other studies have analyzed accident time, weather-related road conditions, and climate-related factors. We analyzed the frequency of traffic accidents by time, and found a significantly higher frequency of traffic accidents at times other than daytime. Previous studies have reported that fatigued driving causes a high frequency of accidents at dawn and at night, disproportionately affecting the major occupational groups of drivers and passengers who are active at these times. Therefore, future studies should conduct occupation-specific analyses [15]. In the analysis of risk factors of traffic accidents conducted by Chen et al. [16], accident occurrence and severity were likewise found to be significantly higher in the early morning hours than at other times. According to Wu et al. [17], who studied the risk of accidents on sunny and foggy days, the risk of accidents on foggy days was significantly higher, especially near highway ramps. In addition, in a report that studied the correlation between meteorological factors and the risk of accidents, the risk of accidents was high in snowy, icy, and slippery road conditions [18-19]. In this study, time and meteorological variables such as weather, road conditions, and temperature at the time of the accident were collected based on trauma data and the weather log information at the time of the accident. Relative to sunny conditions, the incidence of traffic accidents was about twice as high on wet roads, and the incidence of accidents on icy roads and in sub-zero temperatures was $4-5$ times higher. In addition, the frequency of traffic accidents in the presence of fog was 3 times higher.

Regardless of vehicle type, the highest severity was found for patients in the driver's seat, followed in order by the passenger seat and rear seat. According to Atkinson et al. [20], the severity of the injuries of front row passengers in front crash accidents was higher than those of second-row passengers. In a study by Miltner et al., it was reported that the driver's head injuries were more severe than those of other front seat occupants in car-to-car head-on collisions. There have been reports that drivers had more severe head injuries. In addition,
Mayrose et al. [21] showed that patients in the rear row seat had less severe injuries and a high survival rate. The abovementioned findings are consistent with the results of this study, but Mitchell et al. [22] showed higher injury severity among rear-seat passengers than among frontseat passengers. The differences in existing research results seem to be due to differences in the direction of the vehicle collision, the accident mechanism, and the study design. In this study, since the research was conducted by examining 119 records retrospectively, detailed accident records could not be analyzed, and it was not possible to analyze accident-related variables such as rescue time and arrival time from the scene of the accident to the hospital. In the future, further studies should control for relevant variables, unify the descriptions of accident mechanisms, and assess severity according to the presence or absence of safety devices.

A limitation of this study is that patients with relatively low-severity injuries presented to the regional trauma center. Moreover, since the study only analyzed traffic accidents on highways near the hospital, it is not necessarily representative of highway traffic accidents in Korea as a whole. A future analysis of national data will lead to more generalizable results. In addition, the analysis of traffic accidents around tunnels was hindered by a lack of sufficient data on whether the accidents took place on access roads to the tunnel, the inside of the tunnel, or the exit from the tunnel, so it was not possible to study the chain of events involved in collisions due to road conditions and visual impairment. Further research on this topic is necessary. Moreover, when analyzing the severity of patients' conditions, data on whether seat belts were worn and whether airbags were operated were insufficient, so these factors could not be analyzed.

\section{CONCLUSION}

In highway traffic accidents, the severity of trauma to the driver and passengers was significantly different depending on the type of vehicle, and the frequency and severity of accidents increased depending on the curve of the road, inclement (rainy, snowy, or foggy) weather, and the condition of the ground. Based on this study, consideration 
should be given to expanding the scope of trauma treatment activation to include environmental factors.

\section{CONFLICTS OF INTEREST}

No potential conflict of interest relevant to this article was reported.

\section{INFORMED CONSENT}

This type of study does not require informed consent.

\section{REFERENCES}

1. Ministry of Land, Infrastructure and Transport. Vehicle registration status [Internet]. Sejong: Ministry of Land, Infrastructure and Transport 2020 [cited 2020 Sep 29]. Available from: https:// www.index.go.kr/potal/main/EachDtlPageDetail.do?idx_ $\mathrm{cd}=1257$.

2. Shim J, Yu J, Park J, Sim G. Estimation of transport accident cost in 2016 [Internet]. Sejong: The Korea Transport Institute 2018 [cited 2020 Oct 19]. Available from: https://www.koti. re.kr/user/bbs/BD_selectBbs.do?q_bbsCode $=1017 \&$ \&_bbscttSn=20190218133719694\&q_clCode=2\&q_art=N.

3. Çelik AK, Oktay E. A multinomial logit analysis of risk factors influencing road traffic injury severities in the Erzurum and Kars Provinces of Turkey. Accid Anal Prev 2014;72:66-77.

4. Ratanavaraha V, Suangka S. Impacts of accident severity factors and loss values of crashes on expressways in Thailand. IATSS Research 2014;37:130-6.

5. Hijar M, Carrillo C, Flores M, Anaya R, Lopez V. Risk factors in highway traffic accidents: a case control study. Accid Anal Prev 2000;32:703-9.

6. Lee JY, Chung JH, Son BS. Analysis of traffic accident severity for Korean highway using structural equations model. Journal of Korean Society of Transportation 2008;26:17-24.

7. Lee JH, Hong KJ, Shin SD, Ro YS, Kim JE, Ahn KO. Association of road type of traffic accident with mortality and disability of passengers transported by 119 fire department ambulance due to motor vehicle collision. J Korean Soc Emerg Med 2016;27:389-95.
8. Anastasopoulos PCh, Shankar VN, Haddock JE, Mannering FL. A multivariate tobit analysis of highway accident-injury-severity rates. Accid Anal Prev 2012;45:110-9.

9. Roshandel S, Zheng Z, Washington S. Impact of real-time traffic characteristics on freeway crash occurrence: systematic review and meta-analysis. Accid Anal Prev 2015;79:198-211.

10. Yannis G, Theofilatos A, Pispiringos G. Investigation of road accident severity per vehicle type. Transportation Research Procedia 2017;25:2076-83.

11. Liu G, Chen S, Zeng Z, Cui H, Fang Y, Gu D, et al. Risk factors for extremely serious road accidents: Results from national Road Accident Statistical Annual Report of China. PLoS One 2018;13:e0201587.

12. Han X, Shao Y, Pan B, Yu P, Li B. Evaluating the impact of setting delineators in tunnels based on drivers' visual characteristics. PLoS One 2019;14:e0225799.

13. Gårder P. Segment characteristics and severity of head-on crashes on two-lane rural highways in Maine. Accid Anal Prev 2006;38:652-61.

14. Jones AP, Haynes R, Harvey IM, Jewell T. Road traffic crashes and the protective effect of road curvature over small areas. Health Place 2012;18:315-20.

15. Zhang G, Yau KK, Zhang X, Li Y. Traffic accidents involving fatigue driving and their extent of casualties. Accid Anal Prev 2016;87:34-42.

16. Chen $\mathrm{H}$, Cao L, Logan DB. Analysis of risk factors affecting the severity of intersection crashes by logistic regression. Traffic Inj Prev 2012;13:300-7.

17. Wu Y, Abdel-Aty M, Lee J. Crash risk analysis during fog conditions using real-time traffic data. Accid Anal Prev 2018;114:4-11.

18. Malin F, Norros I, Innamaa S. Accident risk of road and weather conditions on different road types. Accid Anal Prev 2019;122:181-8.

19. Shin KH, Park DH, Yoon YS, Kim YW, Park KH, Sun KH, et al. The relationship between rainfall and traffic accident patients in Busan. J Korean Soc Emerg Med 2016;26:443-8.

20. Atkinson T, Leszek Gawarecki, Tavakoli M. Injury severity data for front and second row passengers in frontal crashes. Data Brief 2016;7:839-43.

21. Mayrose J, Priya A. The safest seat: effect of seating position on occupant mortality. J Safety Res 2008;39:433-6.

22. Mitchell RJ, Bambach MR, Toson B. Injury risk for matched front and rear seat car passengers by injury severity and crash type: an exploratory study. Accid Anal Prev 2015;82:171-9. 